\title{
En el vientre de la redoma: los genios en Las mil y una noches
}

Juan Roberto Calderón Benavides Cristián Marcelo Sánchez Cascante

\section{Una palabra y muchos significados}

La palabra genio proviene del árabe Ŷinn, derivada de la raíz $\hat{Y}$ anna que significa cubrir, esconder, hacerse oscuro, ser poseído, enloquecer, excitar y también perturbado, cubierto con un velo. Desde su raíz la palabra $\hat{Y} i n n$ invita a descubrir su significado y, a su vez, a revelar la evolución de los genios.

La palabra $\hat{Y} i n n$ adopta igualmente el sentido de genio, demonio, un ser invisible ni bueno ni malo, que interfiere en la vida de los mortales. Además, está relacionada con $\hat{Y}$ annah, que significa jardín o paraíso, persona muerta, persona de bendita memoria, Jardín del Edén y, a su vez, remite a $\hat{Y}$ unnnah, que expresa protección, refugio, escudo. Por último, $\hat{Y}$ ancan indica corazón y alma'. Así, la palabra genio viene a simbolizar lo irracional, lo oculto y lo inalcanzable, en la cultura árabe.

En el folclore y la mitología islámicos y del Oriente Próximo, los Jinni son espíritus o demonios más pequeños que un ángel. La forma plural del nombre es jinn; la forma femenina, inniyah.

1. Hans Wehr. A Dictionary of Motern Hritten Arabic (Nueva York: Spoken Language Services. 1994) 164. 
De acuerdo con Michel Gall ${ }^{2}$, los $\hat{Y}$ inn se pueden clasificar en $\hat{Y}$ inn del aire, del mar, de la tierra, de los bosques, de las aguas y del desierto, y según los casos, son llamados Efrits, Mareds, Jotrobs, Saalas y Baharis. El término efrit viene de la raíz 'afara, que significa cubrir con polvo o ensuciarse. Un derivado de esta raíz es ta'afrata, que indica comportarse como un demonio o maligno. De allí, que efrit puede traducirse como malicioso, maléfico, travieso, revoltoso, dañino. El segundo tipo de genios es mãrid, cuya raíz proviene de marada, que significa ser refractario, rebelde, ser insolente. Por tanto, mãrid significa rebelde, insurgente, demonio, espíritu, maligno y gigante. Los genios $\breve{G} \hat{u} l$ constituyen un tipo de demonio del desierto que aparece tanto en forma femenina como masculina, monstruo, ogro, bruja; su nombre proviene de la raíz Ğãla, cuyo sentido es arrebatar, secuestrar, destruir y asesinar. Así, la etimología sitúa a los genios en la matriz semántica de la maldad y la rebelión. Para Gall, los genios son la representación del absurdo, y el absurdo como una utilización irracional y no razonada de las fuerzas de la naturaleza.

Lane opina que los genios son una de las más notables de todas las supersticiones de los árabes. Son seres anteriores a los humanos, una clase intermedia de entre los ángeles y los hombres, pero inferior en dignidad a ambos. Están hechos de fuego y pueden asimilar cualquier apariencia. Si desean son invisibles. Pueden ser buenos o malos: si son buenos, son también bellos; si son malvados, su apariencia es fea. Se encuentran en el aire, en las llamas, bajo la tierra y en objetos inanimados, tales como rocas, árboles y ruinas.

En algunos aspectos, se asemejan a los seres humanos: tienen las mismas necesidades corporales, comen y beben, reproducen su especie, y mueren, aunque viven muchos siglos. Pueden reproducirse entre sí y con los humanos (recordemos que algo así sucede con los ángeles del Génesis).

Los jinn son espíritus traviesos que se divierten castigando a los seres humanos y haciéndoles daño, incluso involuntariamente. Así, se

2. Michel Gall, El secreto de las mil y una nociles (Barcelona: Plaza \& Janés. 1976). 
considera que accidentes y enfermedades son obra suya. Gracias a su conocimiento, sin embargo, los seres humanos pueden usar a los jinn para sus propósitos.

Algunos son musulmanes y otros infieles. Estos últimos son llamados Shaytan o diablos, cuyo jefe es Iblis, o sea, Satanás. Los diablos son ginn. Habitan las ruinas, los ríos, los pozos, los baños, los hornos y las letrinas. Las personas toman precauciones cuando utilizan esos lugares diciendo: «Busco refugio en Ti de los diablos machos o hembras». Los torbellinos son motivados por el vuelo de los genios. Por eso dicen: «Hierro, desafortunado», ya que los genios se relacionan con ese metal. Además, las estrellas fugaces (Shihab) son los dardos que arroja Dios contra los genios que se acercan al cielo a escuchar. Cuando los árabes ven esto dicen: «Dios atraviese a los enemigos de la fe». Los genios malignos, los Efrit (ver Corán 27:39) se diferencian de los otros en su maldad y poder. Otro genio maléfico es el Marid.

Los genios pertenecen a una raza prehomínida / preadámica. Se diferenciaban de los humanos pues eran muy poderosos. Cuarenta reyes (setenta y dos en otra versión) prehomínidos tenían cada uno el nombre de Sulaymán, gobernaron a este pueblo. El último de estos reyes se llamaba Gann ibn Gan y fue el constructor de las pirámides. Algunas personas creen que los genios toman su nombre de él: los genios también reciben el nombre Gann.

Formados de fuego o aire, los jinn pueden adoptar tanto forma humana como animal. En ocasiones toman forma de gatos, perros, serpientes y otros animales. Los genios se fijan en los techos o ventanas y arrojan piedras y ladrillos a las calles y patios. Se cree que cada barrio del Cairo tiene sus genios guardianes. Los agatodemontes viven en las antiguas tumbas y templos egipcios. Los fantasmas también reciben el nombre de Efrit. Los gul son maléficos, se alimentan de cuerpos muertos y pueden matar a los mortales ${ }^{3}$.

3. Edward Willam Lane. Mameras y cosmumbes de los egipeios modernos (Madrid: Libertaria / Prodhufi. 1993) 225-230. 
Durante Ramadán están en prisión. En vísperas de la festividad, las mujeres egipcias, para evitar que estos seres entren a las casas, arrojan sal al suelo diciendo: «En nombre de Dios, el Compasivo, el Misericordioso». Algunas personas pronuncian el iqameh (que es casi lo mismo que el adan) en el oído izquierdo. El objetivo de estas ceremonias es preservar al niño de la influencia de los ginn o genii (genios). Otra costumbre, que se observa con el mismo propósito, consiste en decir: «En el nombre del Profeta y de su primo Alí» ${ }^{4}$.

\section{Seres de los umbrales}

Los genios pertenecen a un espacio fronterizo: la montaña $Q \hat{a} f$ o el país de los genios. En la cosmología musulmana, Qâf es el nombre dado al monte que rodea al mundo terrenal, se considera como la montaña madre de todas las montañas del mundo. Estas están ligadas a él por ramificaciones y venas subterráneas, y cuando Dios quiere aniquilar una región cualquiera, se limita a ordenar que se ponga en movimiento una de sus ramas, lo que provoca un temblor de tierra. El $Q \hat{f} f$ constituye el límite entre el mundo visible y el mundo invisible; nadie sabe lo que hay detrás y solo Dios conoce las criaturas que allí viven ${ }^{5}$. Hay una interpretación de Las mil y una noches y una coránica del monte Qâf llevadas a cabo por Michel Gall.

En esa interpretación, la estructura de la monte Qâf es bastante compleja. En un primer nivel se encuentran como equivalentes la serpiente y las tinieblas. La serpiente está efectivamente ligada a la idea misma de la vida, al igual que la tiniebla; en arábigo la serpiente es el-hayyah y la vida el-hayat. Es importante saber que elhay, esunode los principales nombres divinos, que debe traducirse no por «el viviente», sino por «el vivificante» ${ }^{6}$. En el segundo nivel, el

\footnotetext{
4. Lane. 70 .

5. Jean Chevalier y Alain Gheerbrant. Diccionario de los símbolos (1969) (Barceiona: Herder. !999) 725-726.

o. Chevalier. 920 .
} 
infierno y el aire se tornan elementos equivalentes. En ambas interpretaciones del monte en un tercer nivel encontramos el Mar de la eternidad y en él, el pez o la ballena que simboliza la fertilidad. En un cuarto nivel, se observa el toro de una sola cabeza y de 40.000 cabezas, el toro pertenece al ciclo de los símbolos de la creación o cosmoforos ${ }^{7}$. En un quinto nivel, la roca verde que viene a simbolizar la inmutabilidad, la eternidad. En el séptimo nivel, se hallan, por un lado el Ŷinn atlas y, por el otro, el ángel; en ambos casos el símbolo señala una juntura espiritual entre el mundo real y el mundo de lo eterno. Por último, en el octavo nivel, el mundo de genios, formado por siete pisos, tiene su equivalente con la tierra. Es decir, el país de los genios es el mundo de los seres humanos y viceversa, porque al monte $Q \hat{a} f$ solo se puede ascender por artes mágicas o por el éxtasis. Esta descripción de los ocho niveles permite hacer referencia a un sentido expresado en la interpretación de Gall, en los primeros niveles el símbolo comparte el significado de fertilidad con los otros.

Qâf es el decreto, qadar, de Dios que no tiene reposo, por eso las cosas en este lugar están en constante y eterna generación y corrupción. Este decreto divino es doble: decreto anterior, qadar sabiq, decreto global que se halla en la Lámina reservada, es inamovible y en él no es de ninguna utilidad la invocación (para cambiarlo), pues no es posible la excepción, el evitarlo. El otro decreto distingue y particulariza al anterior, qadar mufassil. En él, sí tiene utilidad la invocación y es posible la excepción. A este doble decreto corresponden dos ciencias: la ciencia de lo oculto, 'ilm al-gayba, que corresponde al qadar sabiq, y la ciencia de lo manifiesto, 'ilm al-shaháda, que corresponde al qadarmufassil, y abarca, por tanto, a los seres acabados y a los seres que aparecen y que han salido de la posibilidad, imkan, y están a la vista. Sin embargo, nada se explicita acerca de estas ciencias en Dios. Es el Cálamo, qalam, con el que han escrito las cosas. Es el Alma natural, nafs tabi'iyya, que viene del Alma mayor a la Tierra, abarca

7.

Chevalier, 1002. 
lo que hay bajo la Esfera de la Luna hasta el centro de la Tierra, que son tres cosas: Cuerpo, Espíritu y Alma. El Cuerpo es la Tierra y el agua que hay sobre ella. El Espíritu es el aire que rodea la Tierra. El Alma es la potencia que viene de la Esfera y no tiene subsistencia más que por el Espíritu, ruh, por esto no se separan y están en un rango contiguo.

También es una alusión al Corán. La letra Qâf tiene el significado esotérico del Destino (qader), de lo sagrado, el Corán (alQur'an), del cálamo con que se escribe (Qalam). Los genios y todas las criaturas míticas y mágicas viven en el Qâf al Yabal, el Monte Caf, en el lugar secreto, en lo oculto (al gayb).

\section{Las mil y una noches}

Populares en el folclore de Egipto, Siria, Irán, Turquía y el norte de África, los jinn son familiares en el mundo occidental como personajes de Las mil y una noches ${ }^{8}$, libro que, al entender de Jorge Adoum, es un texto iniciático, cuyo sentido debe ser revelado. Como se verá más adelante, en estos cuentos, dichos seres aparecen con todas las características que se han indicado anteriormente.

En Las mil y una noches, esta figura, que en sus orígenes prehistóricos se generó con base en connotaciones totalmente negativas, se transforma en una figura tan compleja como el tipo de hombres que la creó. Y así, de ser una criatura totalmente rebelde, enemiga del hombre, solitaria y antisocial como un bandido del desierto, poco a poco, a medida que la cultura que lo creó se refina durante el apogeo de las diversas dinastías árabes de la Edad Media, pasa a ser un aliado en la mayoría de las ocasiones; en lugar de un solitario, como aparece en los primeros cuentos de la hermosa colección, se transforma en un ser organizado en reinos que se combaten entre sí al servicio de los ideales del Islam o en su contra; el genio se hace más complejo hasta el punto que su imagen simboliza la unión con Dios en los últimos.

8. Biblioteca de Consulta Microsoft(B) Encarta(B) 2003. (C) 1993-2002 Microsoft Corporation. 
En principio, los genios en las narraciones de Las mil y una noches son seres solitarios que habitan ruinas, letrinas, ríos, pozos, baños y hornos. Son monstruosos, vengativos y violentos; son figuras gigantescas que causan temor:

Vieron que se trataba de un genio, alto de estatura, ancho de cara, y poderoso de pecho, que llevaba un baúl sobre la cabeza ${ }^{9}$.

Pero, de aquí de repente un efrit altísimo, blandiendo en su mano una espada, se acercó al comerciante y le dijo: «Ponte en pie, para que te mate, de la misma manera que has matado a mi hijo» (16).

Al fin terminó de salir todo el humo, se condensó, se removió y se transformó en un efrit. Su cabeza se perdía entre las nubes, sus pies se apoyaban en el polvo de la tierra; aquella parecía una cópula; sus manos verjas; sus pies, mástiles; su boca, una cueva; sus dientes, piedras; sus narices, porrones; sus ojos, dos antorchas; sus cabellos, cenicientos, estaban en completo desorden (28).

Un efrit llamado Chirchis b. Rachmus b. Iblis... Si viene el efrit lo mataré, pues soy ducho en el arte de matar a los genios... la tierra se había hundido y había salido un ef rit de cara detestable (86-90).

De repente apareció un efrit en la peor de las figuras: sus manos nos parecían rastrillos; sus pies, columnas; sus ojos, un par de tizones echando chispas (96).

O en su defecto, son mujeres, efritas que se unen con los seres humanos y los protegen de los magos persas, los genios, las brujas y los demonios.

No obstante, en el segundo tomo de Las mil y una noches, se ve a los genios en una sociedad más sofisticada, pasan de poblar los

9. Anónimo, Las mil yumanocikes: Tomo 1. Traducción de Juan Vernet (Barcelona: Planeta. 1997)

9. En adelante se indicará solamente el número de la página citada. 
páramos, los desiertos y las rocas, hasta formar una sociedad mucho más compleja, donde encontramos:

Somos siete reyes y cada uno de nosotros gobierna siete tribus de genios, demonios y marides; somos siete reyes, pero gobernamos cuarenta y nueve tribus que tiene toda clase de genios, demonios, marides, clanes, servidores que vuelan y bucean; que habitan las montañas, las campiñas, los desiertos y los mares (948). Al llegar a sus inmediaciones vieron que era un efrit cuya cabeza parecía una cúpula enorme; los colmillos eran garfios; las narices, aguamaniles; las orejas, adargas; la boca, una caverna; los dientes, columnas de piedra; las manos, horquillas; los pies, mástiles de un buque; tenía la cabeza en las nubes y los pies se hundían en el suelo, debajo de la tierra (951).

Antes de que pudiera darme cuenta la serpiente se transformó en una muchacha joven, bella, hermosa, reluciente, perfecta y bien proporcionada que parecía ser la luna cuando brilla (1435). Parecía uno de los genios de nuestro señor Salomón, y estaba de pie ante él. Su aspecto terrorífico lo asustó (124).

Apenas había dado una pasada cuando apareció un genio de aspecto horripilante, de una estatura tan enorme que parecía un gigante (128).

Al retirarla salió en su interior un vaso de bronce, cubierto de plomo, y precintado con el sello de Salomón Ben David (sobre ambos sea la paz). El pescador lo retiró, lo rompió y empezó a salir un humo azul que remontó hasta la cúspide del cielo. (...) El humo se transformó en una persona de aspecto espantoso, de talla muy elevada cuya cabeza alcanzaba el monte (265).

Tenía dos grandes alas y cuatro manos, dos de las cuales se parecían a las manos de los hombres y las otras dos a las del león, pues tenía garras. El cabello de su cabeza se parecía la cola de los caballos y sus ojos eran dos carbones encendidos; tenía un tercer ojo en la frente que parecía ser el de un leopardo, 
y de él se desprendían chispas de fuego; era negro y largo y gritaba (274).

Mientras se encontraba sentado llorando, se hendió la pared y salió de ella una persona de elevada estatura y de aspecto tal que producía escalofríos (1471).

Los genios fueron creados de dos seres primigenios llamados Jalit y Malit, con figuras de león y loba, respectivamente.

La longitud de la cola de Jalit era de veinte años de camino. Jalit fecundó la cola de Malit, la cual tuvo siete varones y siete hembras (recordemos el significado esotérico de este número). Entonces se unieron varones y hembras, que obedecieron al padre, salvo uno que se rebeló y fue convertido en gusano; este gusano es Iblis, a quien Dios maldiga. Iblis había sido un arcángel de Dios, a quien sirvió hasta el punto de ser elevado al cielo, colocado junto al Clemente y transformado en jefe de los arcángeles. (...) Al crear Dios a Adán (sobre él sea la paz), mandó Iblis que se prosternarse, pero este se negó a hacerlo. Dios (ensalzado sea) lo desterró y le maldijo. Iblis al reproducirse, dio origen a los demonios. Los seis varones que nacieron antes que él, dieron origen a los genios creyentes, y nosotros somos de su estirpe. Tal es nuestro origen Buluqiya (25).

¿Qué atributos tienen los genios? Pueden ser invisibles a voluntad, veamos:

Los dos genios regresaron al campo enemigo, desenvainaron sus espadas (nadie podía llevar ninguna de esas espadas) y acometieron a los infieles. Dios precipitó el alma de estos al infierno. Los incrédulos, distinguieron dos espadas brillantes que segaban hombres como si segaran granos, pero no vieron a nadie (526). 
Pueden convertirse al Islam, El genio pronunció la profesión de fe y quedó inscrito entre las gentes bienaventuradas (531). Además, la muerte los alcanza igual que a los hombres. Se enamoran y tienen organización política:

El genio quedó dormido de fatiga y roncó. Garib aprovechó para liberarse de las cadenas, cogió una pesada roca, la dejó caer encima de su cabeza, le trituró los huesos y el genio murió en el acto (533).

Yo soy el hijo del rey al Azraq, rey de los genios. Mi padre habita la fortaleza de al Qulzum y le acatan seiscientos mil genios, voladores y buceadores. Ha ocurrido lo siguiente: yo seguía mi camino y me dirigía a mis quehaceres. Entonces te vi, me enamoré de ti, descendí, te rapté de en medio de tus esclavas y te he traído a este alcázar, que está bien construido y en el cual tengo mi morada y domicilio (802).

Somos siete reyes y cada uno de nosotros gobierna siete tribus de genios, demonios y marides; somos siete reyes; pero gobernamos cuarenta y nueve tribus que tiene toda clase de genios; demonios y marides, clanes, servidores que vuelan y que bucean; que habitan las montañas y las campiñas, los desiertos y los mares (948).

Se les espanta, recitando el Corán:

¡Mi señor, del pozo ha subido un efrit! «Ve a buscar cuatro alfaquíes - le dijo el Emir Hasán — para que lean el Corán y se vaya» (642).

Pueden estar bajo el dominio de un verdadero creyente, ya que el hombre es superior a ellos,

Le dijo: «¡Hija mía! Las órdenes del rey de los hombres deben cumplirse y sus decretos hay que acatarlos. Ve junto a esos dos 
hombres, desembrújalos ahora mismo y diles: "estáis bajo la protección del rey de los hombres. Si este se enfada con nosotros nos aniquilará hasta el último: no nos obligues a soportar lo que no podemos”»; «iPadre mío! Pero si el rey de los hombres se enfada con nosotros ¿qué puede hacernos?» Le replicó: « $i$ Hija! Puede dominarnos de varios modos: en primer lugar es un ser humano y está por encima de nosotros; en segundo, es el Vicario de Dios; en tercero es constante en las dos arracas de la plegaria de la aurora» (...) Lo mismo nos ocurre ante cualquier fiel que rece con constancia las dos arracas de la aurora: su voluntad nos obliga (1456).

Los genios pueden tomar forma animal:

«Hemos recorrido el camino de un mes entero» «¿Cómo puede ser?» «Chawdar, sabe que la mula que está debajo de nosotros es un marid, que puede recorrer en un día la distancia de un año; pero por serte agradable ha ido despacio» (382).

En resumen, se puede decir que el genio como figura literaria, mágica y popular es un ser con grandes poderes pero con las limitaciones humanas, como la muerte, la ignorancia, los sentimientos, el amor, la estupidez, la pasión, la sabiduría, etc.

\section{Los Yinn como imagen sufí}

Algunos de los cuentos de la famosa colección están envueltos por una profunda niebla simbólica sufí. En estas narraciones se presenta la separación de un ser humano de su amada, dicha amada es la hija del rey de los genios, quien huye a los lugares más inaccesibles previa invitación al amado para que la siga. El héroe debe recorrer toda una odisea, un viaje imposible a lugares que nadie sabe dónde están. No obstante, con la ayuda de seres más espirituales, guías sobrenaturales, genios y sheijes, logra paso a paso alcanzar con mucho sacrificio la meta. 
La pureza de tu intención, tu amor, tu gran pasión por tu esposa e hijos es lo que te permite realizar tu deseo. Si tú no la amases y no estuvieras enamorado no te hubieses arriesgado por ella. Es necesario que satisfagamos tu deseo y te auxiliemos a buscarla hasta que, en el plazo más breve, si Dios (¡ensalzado sea!) lo quiere, consigas lo que apeteces: Pero sabe, hijo, que tu esposa vive en la séptima de las islas Waq (es interesante el parecido fonético con Qâf) y que de esta nos separan siete meses de viaje de día y de noche (906).

Estas historias representan la visión del tassawf, el sufismo, como la búsqueda del alma por unirse con Dios, la necesidad de conocimiento para alcanzar esa meta, y la importancia del maestro para obtener ese conocimiento. Cuentos como las historias de Hasib Karim al Din, la de Hasán de Basora, el orfebre y la de Sayf al Muluf y Badia al Chamal, son una muestra de esa exposición de la táriqa o método sufí para llegar a la unión con Dios (Fana). No es de extrañar que este tipo de narraciones echen mano a los genios como figuras arquetípicas de lo irracional, lo secreto (gaib).

Como se vio anteriormente, las descripciones de yinnes tienen en común presentarlos de manera horrible y de proporciones gigantescas, salvo en las narraciones donde las yinnas son las hijas del rey de los genios y representan el amor perdido y la búsqueda de la unidad, palabra propia de la jerga sufí. Leamos las palabras del padre de Sayf al Muluf:

Si fuese hija de hombres idearíamos algo para conseguirla, pero esta muchacha es una de las hijas de los genios (...) Yo te traerá cien hijas de reyes y no necesitarás para nada a las hijas de los genios que no son de nuestra especie y sobre las que nada podemos (778).

"iLos hombres no concuerdan con las hijas de los genios;》 le dice Badia al Chamal a Dawa al Jatum. 
En otros momentos se describen las diferentes amadas como beldades capaces de hacer que el hombre más puro se enamore de ellas hasta el punto de realizar un viaje imposible hacia ningún lugar conocido. En el cuento de Hasán se describe a la princesa de los genios con las siguientes palabras:

El muchacho quedó prendado al contemplar su belleza, hermosura, su talle y bellas proporciones. Al volver la vista contempló a la muchacha mayor, que estaba desnuda y descubrió entre sus muslos una cúpula magnífica, redondeada con cuatro pilastras: parecía un tazón de plata o de cristal que recordaba el decir del poeta $(850)$.

Recordemos que estas son las únicas excepciones a la descripción horrible de los genios, aún de otros genios femeninos.

\section{El anillo de Salomón}

Es indispensable recordar que los genios tienen una relación muy estrecha con el anillo de Salomón, que es una estrella de seis puntas en cuyo interior se encuentra escrito el centésimo nombre, el nombre verdadero de Dios. Para los musulmanes Dios tiene 99 nombres conocidos, el último es el verdadero y su conocimiento encierra el poder de dominar a los genios y a los elementos. Affán, un sabio judío, menciona en uno de los libros que lee Baluqiya: «En uno de sus libros constaba que todo aquel que se pusiese el anillo de Salomón podría mandar a los hombres, a los genios, a los pájaros, a los animales y a todos los seres creados» (12).

En el texto de Las mil y una noches, se observa como los genios evolucionan de seres solitarios, escondidos en ruinas, árboles, desiertos, letrinas, torbellinos, hasta formar tribus y reinos que luchan entre sí, esto quizás debido a la sofisticación de la misma cultura árabe.

Queda pendiente el estudio de un aspecto alquímico, cuyo comportamiento no ha sido analizado en relación con los genios, si se rememora que su origen está en el fuego, y son dominados por un anillo mágico en el que está escrito el nombre secreto de Dios. 